\title{
New ways of visualization in laparoscopic surgery
}

\author{
Bartłomiej Grobelski, Dominik A. Walczak, Zbigniew Pasieka \\ Department of Experimental Surgery, Medical University of Lodz, Poland
}

Videosurgery and other miniinvasive techniques 2010; 5 (3): 120-128

DOI: 10.5114/wiitm.2010.16425

\begin{abstract}
Scientific achievements enabled tremendous progress of surgical minimally invasive methods in the $20^{\text {th }}$ century. Laparoscopy and endoscopy became everyday diagnostic and therapeutic tools of modern medicine. Despite its irrefutable opportunities and advantages, classical minimally invasive surgery still has substantial limitations. These include: two-dimensional visualization without depth, a small field of view, and the necessity of precise hand-eye coordination. That is why pressure is placed on manufacturers of endoscopic devices to surmount these technical obstacles. To write this paper we searched databases for articles on new means of visualization in laparoscopic surgery. We discuss augmented reality, three-dimensional vision and image-guided surgery.
\end{abstract}

Key words: endoscopy, laparoscopy, three dimensional visualization, augmented reality, display system

\section{Introduction}

Progress in endoscopy has been a complicated process, with its beginnings dating back to antiquity. Back in the $4^{\text {th }}$ century B.C., Hippocrates in his "On Haemorrhoids" described the technique of endoscopic examination of the rectum in a living patient. During the following ages, endoscopy progressed due to such scientists as Avicenna and Abulcasis, who perfected methods of illumination and optics, which would allow for in vivo examination of the human inside. Another milestone was the achievements of Philipp Bozzini, who in 1806 during a scientific meeting in Frankfurt presented a "light-guide" (Lichtleiter). Skilfully combining previous discoveries of science and inventions of technology, he constructed a tube which allowed for examination of the urinary tract, rectum and oesophagus. His discovery was soon given a negative opinion by the University of Vienna and forgotten [1]. The word "endoscopy" was used for the first time by the French surgeon Antoine Jean Desormeaux, who proved not only the diagnostic but also the therapeutic value of l'endoscopie in
1853 by removing papilloma of the urethra [2]. Thanks to his accomplishments, endoscopy was to turn into a powerful surgical tool in the future [3].

Laparoscopy is a method of performing intra-peritoneal surgery under endoscopic guidance. Its beginnings can be sought in the development of insufflation methods by Georg Kelling at the beginning of the $20^{\text {th }}$ century. He showed that inflation of the peritoneum with air can stop haemorrhage. He inflated canine peritoneal cavities with air up to $100 \mathrm{mmHg}$, calling this procedure a "celioscopy". This invention was applied by Hans Christian Jacobaeus, who performed the very first laparoscopic procedure in a living human on 10 July 1910. By describing a case of laparoscopic treatment of liver cirrhosis in Münchener Medizinische Wochenschrift, he introduced laparoscopy permanently into the armamentarium of surgical methods [3-5]. In the 1960s and 70s laparoscopy became an increasingly important element of gynaecological practice, which in turn drove progress in its technique. Electrocoagulation, liberation of adhesions, cyst removal, taking a biopsy and tubal ligation were introduced. Unfortunately more 
complicated procedures, such as appendectomy and cholecystectomy, were still out of reach. Further progress became possible with the invention of video techniques allowing for real-time presentation of an augmented picture on a television screen. The first known laparoscopic procedure with application of video methods was a cholecystectomy performed by Phillip Moulet in 1987 [3, 6]. In 1997 Anthony Kalloo, during the annual meeting of the American Society of Gastrointestinal Endoscopy, said that one day surgeons would be able to remove the gall bladder without leaving a visible scar on a patients' body. His prediction, met coldly and without belief at that time, came true 7 years later, when he performed the first transgastric peritoneoscopy in a pig [7]. In 2007 natural orifices were used for the first endoscopic cholecystectomy [8].

Endoscopic methods and techniques, which allow for operating below patients' skin without major incisions, perfected for so many years, have now undoubtedly become most frequently used by surgeons, gynaecologists, and gastroenterologists. Further progress in surgery aims at minimization of the operative access by perfecting established endoscopic techniques. Minimally invasive technique still has many limitations. The problem of visualization method remains a crucial task to be solved. No matter if it is laparoscopy or minimally invasive surgery, only a small-field two-dimensional view with no depth is available to a surgeon working with endoscopy. This complicates the coordination of the hand and eye [9]. As 97\% of errors during laparoscopic cholecystectomy result from visual misperception, invention of an appropriate visualization technique seems essential for progress in non-invasive surgical methods [10]. Contemporary technological achievements - new camera types, monitors, 3D technology - seem to provide solutions which will allow further advancement.

\section{Classical laparoscopy Laparoscope}

A laparoscope is a rigid telescope with two optic channels: one for illumination of the operative field, the other for viewing of this area. The whole instrument is supplied with a sophisticated system of lenses, which prevents light beam dispersion and assures perfect resolution of the picture [11]. Due to the angle between the longitudinal axis of the laparoscope and the axis of the anterior lens direct and oblique vision laparoscopes can be distinguished. Direct optics give a wider view angle and brightness and observed actions are visible as a stable picture and can be performed in a more intuitive manner, which results in fewer mistakes. It is of crucial importance for surgeons not too familiar with endoscopic methods. On the other hand, oblique optics allow one to rotate the laparoscope freely to see the operative field from nearly all directions, which is useful in more complicated procedures [12]. Application of a flexible laparoscope with a changeable view angle seems the best solution. This is only possible due to modern materials applied in construction of endoscopes. There are two types of such endoscopes. Construction of the first one is similar to a classical gastroscope, but at its joint it is supplied with a bundle of optical fibre, which transmits the picture as a set of light rays. Another system utilizes photosensitive CCD (chargecoupled device) or CMOS (complementary metaloxide-semiconductor) transceivers, which turn the picture of the patient's inside into an electric signal. So far, neither of these systems is broadly applied and studies by Perrone et al. did not confirm superiority of flexible laparoscopes to the rigid ones [13].

Laparoscopes of 5 and $10 \mathrm{~mm}$ diameter are the most popular. Due to technological progress, minilaparoscopes with diameter from 2 to $5 \mathrm{~mm}$, and even less than $2 \mathrm{~mm}$ (called microlaparoscopes), could be constructed. To do this, standard cylindrical Hopkins lenses had to be substituted with a bundle of numerous parallel optic fibres. Such instruments are used mostly for explorative diagnostics of the peritoneal cavity and sometimes for uncomplicated operative procedures. Contemporary mini- and microlaparoscopes have inferior depth of field and a visible field narrower by $40 \%$ and are extremely fragile. They have however some unquestionable advantages: possibility to perform the procedure under local anaesthesia with minimal sedation, shorter hospitalization, minor pain and small incision with improved cosmetic effect and minimal risk of herniation within the operative wound [11, 14-16].

\section{The camera}

The video camera is the most expensive and sophisticated part of conventional laparoscopic equipment. Sharpness and quality of the presented picture depend mostly on this item. Cameras are usually placed behind the parts introduced into 
a patient's body. New generation cameras are fitted with a CCD transceiver [11]. Function of the system is based on the so-called internal photoelectric effect. Light beams (photons) hitting each pixel of the transducer free some electrons. This in turn results in a difference of electrical potentials, and hence in electric voltage, which can be translated into the video picture. The CCD itself does not distinguish the colours, but is able to measure luminous intensity. To obtain information on the colour, a mosaic filter transparent to a defined wavelength (i.e. red, green or blue light) is placed in front of the sensor. The most modern cameras instead of a unique chip and filter are furnished with a tri-CCD, which means that each of basic colours has its own sensor. The light beam coming from the lens is then diffracted by a set of prisms to form an individual beam for each of the three colours. This solution has greatly increased definition of the image and precision of colour projection.

\section{The monitor and its ergonomic placement}

A chain is only as strong as its weakest link; hence in laparoscopic surgery parameters and setting of the last link, the monitor, are as important as the camera and endoscope. Precision of imaging of the operative field determines whether a surgeon notices minor differences in colour and structure of the tissues, which is necessary for safe and effective surgery without three-dimensional depth. A kinescope monitor (cathode ray tube, CRT) is used most frequently, yet with progress in technology it has to compete with LCD (liquid crystal display) and with the digital projector. Brown et al. tried to assess quality of the image obtained with these three monitors. Their study undoubtedly proved that a golden standard of endoscopic image projection ought to be an LCD monitor placed exactly vis-à-vis an operator. The angle of view is very important in the case of flat LCD monitors, as colour and brightness change when the monitor is located perpendicularly or obliquely to the observer. Such phenomena do not occur with CRT monitors. In this study however, the latest LED monitors were not tested and digital projectors were of the lowest quality [17].

The monitor is usually placed near the operative table, at eye level. This way of imaging affects handeye coordination significantly. First, it is impossible to observe the operative field and movement of one's hands simultaneously. Second, the axis of view of the endoscope rarely matches the natural axis of the surgeon's sight, as if he were looking directly into the operative field. Finally, the arms of the tools act as levers with a fulcrum at the site of the skin incision and hence real action with tool handles is a mirror of the movement of tool tips seen on the monitor [18]. Another consequence of such placement of the monitor is a forced twisting of the neck and body and slight elevation of the head resulting in faster fatigue of the muscles [19-21]. Studies have shown that a neutral position with the head flexed at $15-45^{\circ}$ is most ergonomic. What is more, looking down improves accommodation of the eye lens, causing weariness of the eye less quickly and decreasing the number of headache episodes in a surgeon [21-23].

To find the best position for the monitor, Hanna et al. have assessed the quality of the knots tied in the laparoscopic simulator with different monitor positions. The results confirmed that this task was best performed when the monitor was placed opposite the operator at the level of his hands (level of instrumentation), forcing the sight downwards and securing convergence of the axis of the surgeon's sight and that of the endoscope [24]. Omar et al. proved the benefits of such positioning in even more complicated tasks. They changed the position of the endoscope to obtain 45 and $90^{\circ}$ divergence of the image axis and axis of manipulations performed in the simulator. It is well known that adaptation to the inverted picture needs much greater involvement of the mind, as can be proved by increased activity of the brain cortex. It results in a higher number of mistakes and longer duration of different procedures. This study has shown that directing the eyes downward decreases discomfort of such geometrical transformation and facilitates completing the tasks [25-27].

As already mentioned, the best parameters of the image can be obtained with an LCD screen. Placement of the screen on the patient's abdomen in proximity to the trocars seems like a perfect solution. However, due to the size of the monitor, limited quality of the image seen from such an angle, and the need for sterile cover, this solution did not meet with acceptance. Application of a video projector picturing the image on a light-weight, sterile screen directly above the patient's body is an alternative solution. An additional benefit of such a presentation method is lack of the casing which always encloses classic CRT and LCD monitors. The frame generates a psychological signal that the image is two-dimensional. 
Removal of the casing can help one sense the depth $[28,29]$. Brown et al. have compared results of laparoscopic intestinal suture with application of either a kinescope monitor placed at sight level or a projector showing the picture in proximity to the hands and operative field. They did not find any difference in time of completion of the task, precision of needle manoeuvring and durability of the anastomosis. The authors state that the lack of benefit of the projector was due to low quality of the presented image, which prevailed over the potential advantages of ergonomic position and directing the sight downwards. Only modernization of the projectors and quality of the image equal or superior to modern monitors would enable the benefits of such positioning to be proved [30].

\section{Three-dimensional vision}

While working with available endoscopes, accommodation to performing actions in three dimensions when one can observe only two on the monitor is the most difficult task. Spatial viewing of the reality is a complex process based on three different groups of mechanisms. Knowing these mechanisms, one can try to amend the flat endoscopic image.

The first of them are so-called depth clues, which are very intuitive and can be observed with one eye. Shadows, relative size of the objects, interpolation or movement parallax allow estimation of relative distance of objects observed with just two-dimensional information. For instance, an object which covers another object is located closer to the observer. A thing is attached to the surface where its shadow meets that surface. Using such signals, we are able to watch two-dimensional television and interpret the picture correctly [31].

The second group of mechanisms is that of "egocentric clues", which allow an observer to assess his relation to the subject he is looking at. This kind of perception utilizes the phenomena of:

- accommodation (the nervous system is able to note the tension of the ciliary muscle of the lens dependent on lens shape and hence on the distance to the observed object);

- convergence (tension of the oculomotor muscles changes when the sight is directed to objects placed at different distances from the eye [32, 33]).

The most important, third mechanism of spatial vision is stereoscopy. It depends on the minute diver- gence of the angle at which an object is seen by the left and right eye. As a result, differences in imaging are interpreted by the brain cortex as information on spatial depth. The angular shift decreases with distance to the observed object and both pictures are practically identical over $9 \mathrm{~m}$; hence stereoscopy ceases [28, 34].

To deal with complicated everyday tasks in threedimensional space, one has to use all three groups of mechanisms. In conventional laparoscopy however, most of them are not available:

- There are no shadows - all standard laparoscopes have a source of light located at the very tip of the endoscope, which forms a ring encircling the lens. It is an undoubted advantage as far as the brightness of the image is concerned, yet almost no shadow is visible.

- No stereovision due to the singular optical system of the endoscope.

- Limited utilization of movement parallax due to restricted movements of the endoscope.

- Discordance of accommodation and convergencea surgeon looking at the monitor focuses his sight at the screen surface and not on objects visible "behind" the monitor, so information from egocentric clues is useless [34].

Due to the aforementioned limitations, efforts to eliminate them and introduce spatial view into laparoscopy are under way.

\section{Creation of shadows}

Two systems introducing shadows into an endoscopic image are now used. In the first one the shadow is formed with trocars integrated with an accessory light source. In the second one, the ring of light routinely surrounding the anterior lens of the laparoscope is substituted with semilunar-shaped illumination behind the lens inside the body of the laparoscope [34, 35].

Researchers from Dundee University directed by Alfred Cuschieri tried to assess the benefits of shadow creation during endoscopic procedures and define an optimal illumination method to form the shadowing. In experiments performed in a laparoscopic simulator they showed that the results are much better when separate ports (trocars) are used for visualization and lighting, and the axis of the laparoscope does not coincide with the axis of illumination and thus shadows can be formed [35]. Additionally, the 
researchers observed that intensity of the shadowing is equally important, and too much shadow can result in a larger number of mistakes. What is more, location of the source forming the shadow is as important. The results proved the advantage of top light over one from the side [36]. Concordance of this conclusion with the natural human preference and practice to observe objects lit from above by the sun or other sources of artificial light ought to be noted.

\section{D laparoscope and means of presentation of three-dimensional image}

The most precise information on the spatial structure of reality is obtained due to stereoscopy. It was transferred and applied in stereoendoscopy. An image in this technology can be obtained with a one or two-lens system. The two-lens system is supposed to imitate human eyes, only on a smaller scale. It is composed of two laparoscopes in a single body and two cameras taking slightly different pictures [32]. An advantage of this technique is a very bright image of very high quality. However, it also has numerous faults and limitations. First, generated pictures differ not only in the angle of viewing, which is definitely beneficial, but also in brightness, colour, sharpness and optical deformity. These can result in side effects such as headache, nausea or fatigue of vision. Also, the instrument applied in this method is relatively large and not too convenient [31]. On the other hand, a system with a single lens uses a standard endoscope and a key element is an extension mounted proximally, which separates the image on the left and right [37]. Van Bergen et al. have shown that registration of the image with a two-channel system has greater potential than a single-channelled 3D laparoscope. A surgeon can perceive the depth better, and work more safely and faster. However, two telescopes prevent construction of a fibrescope useful in all situations [38]. As one can see, neither system is perfect, hence the research on creating technology which would combine the advantages and minimize the faults of both conceptions.

The first technology was produced by Fujinon and is closely related to the two-lens system. This innovation is based on application of two video chips at the end of an endoscope. Both images are digital and devoid of optical deformity caused by classical cylindrical lenses. Unfortunately, problems related to other differences in the image still remain. What is more, the distance between the chips let the diameter of the equipment be decreased and hence the 3D effect is hardly visible [31].

The company Visionsense has proposed a totally different solution, constructing an endoscope with an assembly of anterior lenses, positioned in front of a single video chip, reminiscent of an insect's eye. A system of thousands of microscopic lenses results in numerous, slightly shifted images which are then analysed with a special computer algorithm, which separates the images into left and right ones and thus a stereoscopic video picture is generated. Using a single CCD transducer bypasses problems associated with two-channel technologies. It ought to be mentioned that the data obtained also contain information on spatial depth, which potentially could allow for hybrid visualization, for instance for matching with pre-operative computed tomography. According to the inventors, the results of performed operations prove the superiority of this laparoscope over a classic one [39].

\section{Main limitations of classical visualization}

A common problem of all stereoscopic systems is that they are dependent not only on the technology which creates 3-dimensional images, but also on the method of their presentation. Although theoretically ideal for this purpose, multi-planar holographic visualization is beyond the limits of contemporary technology. Modern methods are based on the concept of presenting a different picture to each eye via a video monitor or head-mounted display (HMD) [31]. When a 3D television screen is used, two images are presented one after another with frequency of $120 \mathrm{~Hz}$. To make sure the observer senses a three-dimensional effect, he has to use special glasses separating the image for each eye. This technology can be either active or passive. In an active system, the surgeon wears a pair of glasses supplied with a shutter of liquid crystal, which switches itself from transparent to non-transparent. Full synchronization with the monitor via infrared ray results in presentation of only the appropriate image for the eye. Although loss of brightness is much less than in the passive system described further on, such glasses require a battery, are not very convenient and also shake a little [31, 32, 40]. An alternative means of separation of the image is to polarize it. In a passive system filters polarize both images at a $90^{\circ}$ angle. Wearing glasses trans- 
parent to light rays in only one plane, one is able to see a stereoscopic image. The system is relatively cheap, and the glasses are lighter and more comfortable.

A video helmet (HMD) is a technologically most advanced device. It displays two different pictures on two small LCD monitors placed in front of each eye. As there is no need for polarization, the image has better quality. What is more, the helmet is mobile, and hence the natural hand-eye axis can be supported with movement of the head towards the operative field, which improves the ergonomic position and hand-eye coordination [32]. There are numerous HMD screens, with some resulting in complete immersion, i.e. totally cutting off the reality of the surrounding operating room. This however is not beneficial, as the surgeon cannot adequately react to situations which require looking directly at the patient or the tool in use. On the other hand, receiving simultaneous visual information from the operative field and the environment can result in somatic disorders such as headache, vertigo or nausea. They occur due to discordance of the data with the position of the head and body movements [33].

There are many contradictory reports comparing aforementioned stereoscopic systems with classic mono-ocular ones. Simulation tests of moving various objects, suturing or tying knots gave confusing results. Some studies showed significantly better results, shortening of the task completion times, improved precision and a smaller number of mistakes. Others could not confirm any difference [33, 34, 41-43]. Similar ambiguity was observed in clinical trials. Hanna et al. [35] performed a randomized trial to assess the effects of stereovision during laparoscopic cholecystectomy. As in the simulator, no difference in duration of surgery and number of mistakes could be confirmed but the number of negative somatic disturbances was significantly higher in comparison to the classical way of visualization. On the other hand, Wenzl et al., who tried to prove superiority of 3-dimensional endoscopy for gynaecological diagnostics, drew totally different conclusions [37]. What is interesting, only every third surgeon whose results were ranked better with $3 \mathrm{D}$ vision was willing to choose this system for everyday practice [32].

\section{Augmented reality}

Augmented reality (AR) can be understood as a compromise between virtual reality (VR), i.e. com- pletely artificial, computer-generated images, and telepresence, i.e. true, overlaid images. In contrast to VR, where an operator is completely "submerged" in a fake environment, the user of augmented reality can see the surrounding, real world with virtual objects overlaying it. Thus, AR contributes to the reality instead of substituting for it. Virtual and real objects coexist in the same space, creating an effect which one could see in the movie "Who Framed Roger Rabbit?". Ronald Azuma presented a definition synthesizing the features of augmented reality. Thus, $A R$ is a system characterized by the following three properties:

- it merges the real world with virtual reality,

- it is interactive in real time,

- it can be seen in three dimensions [44].

A video helmet is the instrument used most often for blending a virtual image with a real one, yet application of other technologies based on monitors or mono-ocular systems is also possible. Augmented reality is now used in many spheres of science and technology. The first medical application was made in 1986 in neurosurgery during brain tumour resection [45]. AR then allowed creation of 3-dimensional navigation to secure minimal brain tissue damage. Its clinical use in general surgery is much more difficult. In neurosurgery, the skull as a rigid construct was a perfect point of relation. What is more, movements of structures of the brain were very limited and their shape was not affected by ventilation, heart beat or gas inflation (as during laparoscopy) [46]. However, some progress was possible also in this field, especially in liver surgery [47] and breast surgery [48]. Now efforts are being made to apply augmented reality in laparoscopic surgery. There are two main concepts how to create the AR image during laparoscopy:

The first one is not different from neuronavigation, already assessed clinically. Prior to surgery, a patient has to undergo computed tomography. From received images, three-dimensional reconstruction of the operated body region and organs is made. This allows precise planning of the surgical procedure, resection margins, pre-determination of placement of the trocars, laparoscope and surgical tools to secure the best view and access to the operative field. The very first such procedure was performed in Strasbourg in 2008 in a 45-year old patient with 1-cm Conn's adenoma of the right adrenal gland. Throughout the surgery, the surgeon could use two monitors: one with a standard image, the other one with over- 
laid three-dimensional reconstruction of the organs. According to the authors, in a discussed case of adrenalectomy, the use of augmented reality was particularly helpful in identification of the suprarenal vein, which could be precisely determined with $A R$ imaging, and its safe isolation from virtually transparent fat tissue was enabled [49].

The second concept of imaging utilizes structural light. In this technology, a special projector emits light beams (called high frequency rasters), which form linear illuminations on the surface of encountered objects. Observing this striatum at the proper angle and analysing visible deformity provides 3dimensional information. With this technology, Chapel Hill scientists have created a 3D endoscope. They used a standard laparoscope as a structural light source. A video camera mounted alongside the metal tube facilitated observation of the pattern of bands and transmission of information to the computer for further analysis. The image was presented to the surgeon with an HMD optical display. The operator could view the patient's inside through a virtually generated window on the skin, showing organs and tissues in real time. So far, this innovative system has not been used in humans and all the experiments were performed on phantoms only. However, the potential of such a device in laparoscopic surgery was proven. For instance, in one of the experiments a surgeon guided by coloured 3D texture successfully needled a tiny plastic object inside a phantom's abdominal cavity [9]. Additionally, application of augmented reality allowed for axial visualization as during regular open surgery, which is known to significantly improve eye-hand coordination.

Both presented concepts seem to be promising solutions, and can provide many benefits for both patient and physician. Possibly, however, only a merge of pre-operative imaging and reconstruction systems (CT or MRI) with real-time intra-operative navigation (for instance with ultrasonography) and structural light-based three-dimensional vision will allow for more complete visualization than the one we know today. To date, augmented reality is mostly used as a practice model for those surgeons beginning their laparoscopic practice [50-52].

\section{Summary}

During the 23 years since the first video-laparoscopic cholecystectomy was performed, "key-hole" surgery has been accepted as an excellent diagnostic and therapeutic tool. Often laparoscopic procedures proved to be superior to classical ones in general [53] and paediatric surgery [54], gynaecology and urology [55]. As mentioned above, despite its numerous advantages, videosurgery also faces many limitations. Efforts to overcome these limitations described in this article, although effective in many experimental trials, have not met broad acceptance in clinical practice so far. Hence, further development of these technologies seems as necessary as searching for completely new solutions. Probably in the near future cooperation of surgeons, diagnosticians, engineers and computer graphic experts will result in building a device capable of transmitting real time images of the patient's inside onto the surface. Combined with previous diagnostics, precise definition of the aim of the procedure and identification of index information (invisible blood vessels, extension of the planned resection, differentiation between visually similar tissue structures and their borders) will allow for incredible progress of minimally invasive techniques.

\section{References}

1. Engel RM, Bozzini P. The father of endoscopy. J Endourol 2003; 17: 859-62.

2. Léger P. Antonin Jean Desormeaux. Prog Urol 2004; 14: 1231-8.

3. Lityński GS. Śladami pionierów laparoskopii. In: Kostewicz W. Chirurgia laparoskopowa. Wydawnictwo Lekarskie PZWL, Warszawa 2002; 19-32.

4. Lityński GS. Laparoscopy - the early attempts: spotlighting Georg Kelling and Hans Christian Jacobaeus. JSLS 1997; 1: 83-5.

5. Hatzinger M, Kwon ST, Langbein S, et al. Hans Christian Jacobaeus: inventor of human laparoscopy and thoracoscopy. J Endourol 2006; 20: 848-50.

6. Spaner SJ, Warnock GL. A brief history of endoscopy, laparoscopy, and laparoscopic surgery. I Laparoendosc Adv Surg Tech A 1997; 7: 369-73.

7. Kalloo AN, Singh VK, Jagannath SB, et al. Flexible transgastric peritoneoscopy: a novel approach to diagnostic and therapeutic interventions in the peritoneal cavity. Gastrointest Endosc 2004; 60: 114-7.

8. Marescaux J, Dallemagne B, Perretta S, Wattiez A. Surgery without scars: report of transluminal cholecystectomy in a human being. Arch Surg 2007; 142: 823-6.

9. Fuchs H, Livingston MA, Raskar R, Colucci D. Augmented reality visualization for laparoscopic surgery. Lect Notes Comput Sci 1998; 1496: 934-43.

10. Way LW, Stewart L, Gantert W, et al. Causes and prevention of laparoscopic bile duct injuries: analysis of 252 cases from a human factors and cognitive psychology perspective. Ann Surg 2003; 237: 460-9. 
11. Kostewicz W. Sprzęt, narzędzia, szwy i protezy używane w chirurgii laparoskopowej. In: Kostewicz W. Chirurgia laparoskopowa. Wydawnictwo Lekarskie PZWL, Warszawa 2002; 42-68.

12. Kang SK, White PS, Lee Ms, Ram B. A randomized control trial of surgical task performance in frontal recess surgery: zero degree versus angled telescopes. Am J Rhinol 2002; 16: 33-6.

13. Perrone JM, Ames CD, Yan Y. Evaluation of surgical performance with standard rigid and flexible tip laparoscopes. Surg Endosc 2005; 19: 1325-8.

14. Kolios E, Moran ME. Microlaparoscopy. J Endourol 2004; 18: 811-7.

15. Ikeda F, Abrăo MS, Podgaec S, et al. Microlaparoscopy in gynecology: analysis of 16 cases and review of literature. Rev Hosp Clin Fac Med S Paulo 2001; 56: 115-8.

16. Tu FF, Advincula AP. Miniaturizing the laparoscope: current applications of micro and minilaparoscopy. Int J Gyneacol Obstet 2008; 100: 94-8.

17. Brown SI, White C Wipat K, et al. Characterizing the "gold standard" image for laparoscopic surgery. Surg Endosc 2004; 18 1192-5.

18. Breedveld P, Wentink M. Eye-hand coordination in laparoscopyan overview of experiments and supporting aids. Minim Invasive Ther Allied Technol 2001; 10: 155-62.

19. Matern U, Faist M, Kehl K, Giebmeyer C. Monitor position in laparoscopic surgery. Surg Endosc 2005; 19: 436-40.

20. Zehetner J, Kaltenbacher A, Wayand W, Shamiyeh A. Screen height as an ergonomic factor in laparoscopic surgery. Surg Endosc 2006; 20: 139-41.

21. Veelen MA, Jakimowicz JJ, Goossens RH, Meijer DW. Evaluation of the usability of two types of image display systems, during laparoscopy. Surg Endosc 2002; 16: 674-8.

22. Burgess-Limerick R, Mon-Williams M, Coppard VL. Visual display height. Hum Factors 2000; 42: 140-50.

23. Cuschieri A. Epistemology of visual imaging in endoscopic surgery. Surg Endosc 2006; (Suppl. 2): S419-24.

24. Hanna GB, Shimi SM, Cuschieri A. Task performance in endoscopic surgery is influenced by location of the image display. Ann Surg 1998; 227: 481-4.

25. Omar AM, Wade NJ, Brown SI, Cuschieri A. Assessing the benefits of "gaze-down" display location in complex tasks. Surg Endosc 2005; 19: 105-8.

26. Ittelson WH. Mirror reversals: real and perceived. Perception 1993; 22: 855-61.

27. Bock O, Abeele S, Eversheim U. Human adaptation to rotated vision: interplay of a continuous and a discrete process. Exp Brain Res 2003; 152: 528-32.

28. Cuschieri A. Visual display technology for endoscopic surgery. Minim Invasive Ther Allied Technol 1996; 5: 427-34.

29. Wade NJ. Frames of references in vision. Minim Invasive Ther Allied Technol 1996; 5: 435-9.

30. Brown SI, Frank TG, El Shallaly G, Cuschieri A. Comparison of conventional and gaze-down imaging in laparoscopic task performance. Surg Endosc 2003; 17: 586-90.

31. Szold A. Seeing is believing: visualization systems in endoscopic surgery (video, HDTV, stereoscopy, and beyond). Surg Endosc 2005; 19: 730-3.
32. Pietrzak P, Arya M, Joseph JV, Patel HR. Three-dimensional visualization in laparoscopic surgery. BJU Int 2006; 98: 253-6.

33. Mueller-Richter UD, Limberger A, Weber P, et al. Possibilities and limitations of current stereo-endoscopy. Surg Endosc 2004; 18 : 942-7.

34. Breedveld P, Stassen HG, Meijer DW, Jakimowicz JJ. Observation in laparoscopic surgery: overview of impeding effects and supporting aids. J Laparoendosc Adv Surg Tech A 2000; 10: 231-41.

35. Hanna GB, Cresswell AB, Cuschieri A. Shadow depth cues and endoscopic task performance. Arch Surg 2002; 137: 1166-9.

36. Mishra RK, Hanna GB, Brown SI, Cuschieri A. Optimum shadowcasting illumination for endoscopic task performance. Arch Surg 2004; 139: 889-92.

37. Wenzl R, Lehner R, Vry U, et al. Three-dimensional videoendoscopy: clinical use in gynaecological laparoscopy. Lancet 1994; 344: 1621-2.

38. van Bergen P, Kunert W, Buess GF. Three-dimensional (3-D) video systems: bi-channel or single-channel optics? Endoscopy 1999; 31: 732-7.

39. Y. Kaufman A. Sharon O. Klein D, et al. The three-dimensional "insect eye" laparoscopic imaging system-a prospective randomized study. Gyn Surg 2007; 4: 31-4.

40. Griffin WP. Three-dimensional imaging in endoscopic surgery. Biomed Instrum Technol 1995; 29: 183-9.

41. Minnich DJ, Schell SR. Evaluation of face-mounted binocular video display for laparoscopy: outcomes of psychometric skills testing and surgeon satisfaction. J Laparoendosc Adv Surg Tech A 2003; 13: 333-8.

42. Patel HR, Ribal MJ, Arya M, et al. Is it worth revisiting laparoscopic three-dimensional visualization? A validated assessment. Urology 2007; 70: 47-9.

43. Maithel SK, Villegas L, Stylopoulos N, et al. Simulated laparoscopy using a head-mounted display vs traditional video monitor: an assessment of performance and muscle fatigue. Surg Endosc 2005; 19: 406-11.

44. Azuma R. A survey of augmented reality. Presence: Teleoperators and Virtual Environments 1997; 6: 355-85.

45. Kelly PJ, Kall BA, Goerss S, Earnest F $4^{\text {th }}$. Computer-assisted stereotaxic laser resection of intra-axial brain neoplasms. J Neurosurg 1986; 64: 427-39.

46. Shuhaiber JH. Augmented reality in surgery. Arch Surg 2004; 139: 170-4.

47. Herline AJ, Stefansic DJ, Debelak JP, et al. Image-guided surgery preliminary feasibility studies of frameless stereotactic liver surgery. Arch Surg 1999; 134: 644-50.

48. Sato Y, Nakamoto M, Tamaki Y, et al. Image guidance of breast cancer surgery using 3-D ultrasound images and augmented reality visualization. IEEE Trans Med Imaging 1998; 17: 681-93.

49. Marescaux J, Rubino F, Arenas M, et al. Augmented-realityassisted laparoscopic adrenalectomy. JAMA 2004; 292: 2214-5.

50. Botden SM, Jakimowicz JJ. What is going on in augmented reality simulation in laparoscopic surgery? Surg Endosc 2009; 23: 1693-700.

51. Budziński R, Michalik M, Frask A. Edukacja w chirurgii laparoskopowej. Videosurgery and other miniinvasive techniques 2008; 3: 22-9. 
52. Gruca Z, Kobiela J, Stefaniak T. Przydatność symulatorów w nauczaniu małoinwazyjnej techniki operacyjnej w chirurgii. Videosurgery and other miniinvasive techniques 2008; 3: 30-4.

53. Kawamura H, Yokota R, Homma S, Kondo Y. Comparison of inva siveness between laparoscopy-assisted total gastrectomy and open total gastrectomy. World J Surg 2009; 33: 2389.

54. Ferreira CG, Reinberg O, Becmeur F, et al. Neonatal minimally invasive surgery for congenital diaphragmatic hernias: a multicenter study using thoracoscopy or laparoscopy. Surg Endosc 2009; 23: 1650-9.

55. Hattori R, Yoshino Y, Komatsu T, et al. Pure laparoscopic complete excision of distal ureter with a bladder cuff for upper tract urothelial carcinoma. World J Urol 2009; 27: 253-8. 